In the subthemes main subjects were the need for appropriate care for the long stay patient and the need of ongoing education.

Discussion Both, nurses and physicians recognised a need for change in nursing care for the long stay patient at the PICU. This suits with the changing PICU environment.

Nurses could have a role in bedside procedures such as pain and sedation management and weaning from the ventilator. This will enhance the area of nursing autonomy, control and responsibility and from literature we know satisfaction in the workplace also will grow.

The deployment of a consultative nurse may improve the satisfaction of patients and parents after discharge from the PICU and will unburden the growing responsibility of the nurses on the paediatric ward.

\section{PO-0887 EXPERIENCES AND ATTITUDES OF NURSES CONCERNING COMPLEMENTARY AND ALTERNATIVE MEDICINE METHODS USED BY THEMSELVES AND THEIR PATIENTS}

V Cirik, E EFE, SÖncel, S Gözüm. Nursing Faculty, Akdeniz University, Antalya, Turkey

\subsection{6/archdischild-2014-307384.1509}

Background There has been an increasing interest in CAM methods in recent years, which the importance of evaluating the personal experiences of nurses concerning CAM methods, as well as their attitudes and experiences concerning the use of these methods by their patients.

Aims and objectives The objective of this study is to determine the experiences and attitudes of nurses concerning Complementary and Alternative Medicine (CAM) methods used by themselves and their patients.

Design This is a descriptive study.

Method This study was conducted at Akdeniz University Hospital, Antalya, Turkey, between January and April 2013. 220 $(80 \%)$ nurses working directly on patient care were included in the study. In the study, a questionnaire prepared by researchers was used as a data collection form.

Results It was determined that $85 \%$ of nurses included in the study used one or more CAM methods. Among CAM methods, nurses were mainly acquainted with praying (98.6\%), massage $(95.5 \%)$ and they also used them efficiently. While $8 \%$ of nurses stated that the responsibility of informing patients about CAM methods belonged to nurses, $47.6 \%$ stated that it belonged to doctors. $92.7 \%$ of nurses expressed no negative experience concerning CAM methods used by their patients.

Conclusions It was determined that nurses did not question CAM methods used by their patients and did not consider them among their own responsibilities. The fact that nurses did not have negative attitudes about CAM methods and had positive experiences about patients may enable them to be more active in integrative nursing practices.

\section{PO-0888 ENCOUNTERING THE CANCER: A QUALITATIVE STUDY}

A Gürol, ${ }^{2}$ S Polat, ${ }^{3} \mathrm{MF}$ Polat, ${ }^{4} \mathrm{Z}$ Keskin Yildirim. ${ }^{1}$ Pediatric Nursing, Atatürk University, Erzurum, Turkey; ${ }^{2}$ Pediatric Nursing, Bozok University, Yozgat, Turkey; ${ }^{3}$ Medical Biochemistry, Bozok University, Yozgat, Turkey; ${ }^{4}$ Pediatric Oncology, Atatürk University, Erzurum, Turkey

10.1136/archdischild-2014-307384.1510
Background and aim Getting diagnosed with a cancer is a life crisis for many people. When children, the most precious beings of parents, are diagnosed with cancer, this affects them deeply. This study was designed to determine the views of mothers regarding with the feelings of the mother when their child have received a diagnosis of cancer.

Methods The study used the method of focus group interviews and face-to-face in-depth interviews for qualitative studies. Interviews were held with the mothers of 6 children with cancer on March 2014. Data was collected using a semi-structured questionnaire. The mothers' verbal consents were obtained.

Results Mothers were asked about how they felt when they first heard about the diagnosis. Mother C said, 'You get accustomed to everything; but not that diagnosis. When I first heard about the diagnosis, the hospital literally collapsed on me'. Mother $\mathrm{H}$ said, 'We never expected that; we were just petrified and could eat nothing for days'. Two mothers expressed that the moment was by far the hardest moment of their lives. Regarding the question 'How do you define cancer?', the following statements were made; Mother E, 'It is a disease exhausting hopes everyday', and Mother C, 'I have lost one of my relatives who was diagnosed with cancer. Cancer means death to me'.

Conclusion Diagnosis and treatment of cancer constitute a very challenging process both for the child and parents. Thus, healthcare professionals should provide the convenient support and consultancy for them as from the outset.

\section{PO-0889 NURSING AND MEDICAL FACULTY STUDENTS' TENDENCY OF PATERNALISM FOR PAEDIATRIC PATIENTS}

F Arslan Tas, S Özkan. Faculty of Health Sciences Department of Nursing, Selcuk University, Konya, Turkey

\subsection{6/archdischild-2014-307384.1511}

Background and aim Paternalism for paediatric patients is doctors' or nurses' acts intentionally on behalf of patients according to the purpose of doing good or avoiding harm. It can be against the codes of ethics, children rights and other laws. Paternalism is increasingly regarded as outdated and discussed on developed countries but there isn't any study about it in Turkey.

Methods This descriptive and cross-sectional study was conducted at Selcuk University in March-April 2014. This study aimed to find nursing and medical faculty students' tendency of paternalism for pediatic patients. Study population was 202 students and without sample selection 100 students who agreed to participate voluntarily were included in sample. Data were collected with a survey. Numbers, percentage distribution and chisquare were used to determinate data.

Results Medical faculty (40\%) and most of nursing (76.8\%) students stated they had received training about children rights in their undergraduate education. Significant statistical differences weren't found between the awareness of children rights violations and taking children rights lessons $(p=0.50)$. Using personal experiences (nursing students' 46.4\%; medical faculty students' $61.3 \%$ ) and choosing useful things for children (nursing students' $78.3 \%$; medical faculty students' $74.2 \%$ ) in the process of providing information to parents were found important both nursing and medical faculty students.

Conclusion Even though nursing and medical faculty students expressed similar things during the process of providing information to parents, nursing students were found more sensitive 